\title{
A representação da fome em Ventos do Apocalipse, de Paulina Chiziane
}

\author{
Franciane Conceição da Silva*
}

\begin{abstract}
RESUMO
O estudo analisa o romance Ventos do Apocalipse (1999), da escritora moçambicana Paulina Chiziane, avaliando alguns aspectos estéticos e estilísticos da obra que permitem ao leitor entender o quanto ela se mostra original e inovadora para mostrar que, diante das atrocidades da guerra, perde-se a capacidade de narrar de maneira convencional e, por isso, tornase necessário buscar outras formar de dizer, outros modos de representar.
\end{abstract}

Palavras-chave: Ventos do Apocalipse. Paulina Chiziane. Literatura. Guerra. Representação.

O romance Ventos do Apocalipse (1999), da escritora moçambicana Paulina Chiziane, é uma narrativa com um enredo surpreendente que envolve o leitor do início ao fim. Ventos do Apocalipse narra a história dos moradores das aldeias de Mananga e Macuácua, que são duramente atingidos pela violência da guerra civil moçambicana. Depois de terem suas aldeias destruídas, os refugiados decidem viajar até a aldeia do Monte, local em que a guerra ainda não chegou. A aldeia do Monte é a última esperança do grupo de miseráveis que se vê perdido e desesperado diante da barbárie e da violência. Tal qual na Bíblia Sagrada, o Monte surge como uma espécie de terra prometida, um lugar sagrado em que os refugiados encontrarão o alimento para saciar a fome, água limpa, abrigo e, acima de tudo, a paz tão desejada:

$\mathrm{O}$ choque cede lugar ao medo que aconselha à prudência da fuga. Em todos os cantos a conversa é a mesma: gente, vamos fugir para a aldeia do monte, lugar de paz e sossego onde a história da guerra é apenas um murmúrio desagradável. Lá se constrói uma vida pacífica. Por lá correm águas benditas por todos os vales. Nos riachos residem os espíritos bons que purificam a alma e curam as mágoas. (CHIZIANE, 1999, p. 119).

* Pontifícia Universidade Católica - PUC Minas. Bolsista CAPES. 
Ao perceberem que não lhes restam mais alternativas, os refugiados resolvem fazer a longa caminhada até a "Terra Prometida", seguindo numa fuga desesperada pela floresta, onde muitos perigos os aguardam. Durante os vários dias em que caminham pela floresta traiçoeira e desconhecida, os fugitivos enfrentam diversos obstáculos, alguns enlouquecem diante do horror, outros adoecem e muitos deles morrem pelos mais variados motivos: atacados pelos inimigos ou por animais ferozes, cometendo suicídio, de frio, doenças, e, sobretudo, de fome. A morte torna-se uma indesejável companheira do grupo de fugitivos, que depois de terem presenciado a destruição de sua aldeia e a morte de muitos dos companheiros, são surpreendidos por cenas ainda mais aterrorizantes. Como podemos ver no trecho que segue:

\begin{abstract}
Meu Deus! Há um cadáver a apodrecer e tem a cabeça decepada. Cinco passos adiante a cabeça está tombada, de olhos abertos. Uma criança de nove ou dez meses segura-a forte com os frágeis dedinhos, vira-a e revira-a nervosamente soltando guinchos de fúria. Parece que brinca com ela, mas não, não brinca. Tenta desesperadamente despertar a mãe para a vida. Vejam este rasto, do tronco do cadáver para a cabeça, da cabeça para o tronco. De gatas, o bebê arrastou-se para cá e para lá, o rasto é bem nítido, legível. Tenta puxar a cabeça e juntá-la ao corpo, quer acordar a mãe, reclama o alimento e o carinho que as mãos desumanas usurparam. Esta não morreu agora, a poça de sangue se tornou pedra. A criança está demasiado nojenta, está cagada, mijada, as crostas de sangue coagulado cobrem-lhe as mãos, os dedos, os cabelos, é preciso chamar a coragem de todos os deuses para poder segurá-la porque até os homens mais corajosos se arrepiam perante o expoente máximo do incrível. (CHIZIANE, 1999, p. 169).
\end{abstract}

Em um contexto de guerra, o "expoente máximo do incrível" deixa de ser algo extraordinário e passa a fazer parte do cotidiano. E assim, depois de vinte e um dias encarando as mais terríveis adversidades, os refugiados, finalmente, chegam à Aldeia do Monte. Estão doentes, sujos, raquíticos, famintos e tão desfigurados que são confundidos com fantasmas: "O grupo de crianças levando as cabras à pastagem descobre figuras estranhas caminhando para a aldeia. Assusta-se. Não são seres humanos, parecem figuras fantásticas emergindo das profundezas do inferno." (CHIZIANE, 1999, p. 185).

Depois da confusão inicial, os refugiados são reconhecidos pelos moradores da Aldeia do Monte, que correm 
Ao auxílio dos recém-chegados, alguns deles também foram viajantes involuntários. A aldeia inteira recebe-os e dá-lhes as boasvindas. Por fraternidade. Por solidariedade. Por compaixão. Por curiosidade. Por recordação dos momentos atrozes que passaram, Deus sabe quando e como. (CHIZIANE, 1999, p. 185).

Nos primeiros tempos no novo espaço, os refugiados tentam recuperar suas forças, contando com a solidariedade dos moradores antigos, que não medem esforços para ajudá-los. Em meio às dores inesquecíveis provocadas pela violência da guerra, os de Mananga e Macuácua conseguem se reerguer, pois a Aldeia do Monte oferece-lhes tudo o que precisam para recomeçar: comida, água, terra boa para cultivar. O Monte é o paraíso que tanto sofreram para conseguir alcançar, e é nele que começam a escrever uma nova história. Como se confirma no fragmento em destaque:

Terra de promissão. Campos verdes. Montanhas cobertas de erva e flor. As sementes fizeram-se plantas, fizeram a flor e agora são fruto. Fruto maduro. Os choros dos homens são substituídos por sorrisos e o marfim da boca corre abundante. $\mathrm{O}$ canto dos ndlazis escuta-se à distância, tão suave como a flauta de cana, chegou o momento de paz, a felicidade é agora maior do que nunca. Os camponeses estão libertos de todas as preocupações, finalmente chegou a época da colheita. (CHIZIANE, 1999, p. 261).

A paz tão desejada pelos refugiados se instala na aldeia do Monte. Um novo tempo se anuncia. A tempestade cede espaço à bonança. Todavia, depois de um breve tempo de paz, os moradores da Aldeia do Monte voltam a ser surpreendidos pelos ventos da guerra mortífera. E assim, "a aldeia do Monte recebe o seu baptismo de fogo". (CHIZIANE, 1999, p. 275).

Nesse contexto, depois de familiarizarmos o leitor com o enredo de Ventos do Apocalipse, vamos avaliar alguns aspectos estéticos e estilísticos dessa obra, para entendermos o quanto essa se mostra original e inovadora. Dentre os vários elementos que fazem de Ventos do Apocalipse uma narrativa singular, destaca-se a presença de um narrador que apresenta múltiplas facetas, assumindo a onisciência, mas também uma onipresença. Em um primeiro momento, o narrador é apenas uma testemunha dos fatos, é aquele que contará a história da guerra que destruiu a Aldeia de Mananga: 
As folhas caem no Outono na ceifa do vento. As águas do rio desembocam no mar, voam para o céu e voltam, enchendo de novo os rios. As estações do ano andam à roda. Até nós, seres humanos, morremos para voltar a nascer. Somos a encarnação dos defuntos há muitos sepultados, não somos? A terra gira e gira, a vida é uma roda, chegou a hora, a história repete-se, KARINGANA WA KARINGANA. (CHIZIANE, 1999, p. 22).

No início da história, como mostramos no fragmento acima destacado, o narrador, mantendo certa distância dos fatos narrados, apresenta uma espécie de presságio, alertando o leitor para as tragédias que se aproximam. Com o decorrer da história, quando a violência da guerra manifesta sua face mais bárbara e a Aldeia de Mananga é brutalmente atingida, diante da aflição dos personagens, o narrador já não consegue manter distância dos fatos, sua enunciação deixa de ser feita em terceira pessoa e passa à primeira pessoa. Desse modo, o narrador deixa de ser apenas observador e torna-se parte de um "nós", ou seja, torna-se um dos personagens da história, um dos muitos miseráveis destruídos pela guerra. $\mathrm{O}$ fragmento que segue comprova essa assertiva:

A sociedade está desorientada, deambula nas trevas da amargura, e mais do que nunca precisa de um conforto de espírito. Na aldeia já não há igreja. Restam apenas ruínas do edifício por nós construído com suor e sangue à custa do chicote português. Destruímos esse monumento na euforia, porque tínhamos conquistado a liberdade. (CHIZIANE, 1999, p. 130 - destaque nosso).

Além de manifestar-se como um personagem do romance, que vivencia os fatos narrados, sofrendo as consequências da guerra e toda a violência por ela provocada, o narrador de Ventos do Apocalipse assume muitas outras facetas. E em alguns momentos não sabemos separar a sua voz das vozes das personagens, pois ambas se misturam. Como podemos ver no excerto abaixo:

Minosse abandona o marido pensativo. Caminha apressada. Pegadas estranhas desenham-se bem nítidas na orla do celeiro. São pegadas de botas e em Mananga ninguém as usa porque ninguém as tem. Poucos são os que usam sapatos e só os põem em dias de gala. Que o ladrão é esperto, isso é. Usou as botas para disfarçar a marca do pé, ai meus queridos grãos. Que vou dar ao meu marido? Minosse está mais fula que a galinha chocalheira. (CHIZIANE, 1999, p. 34-35 destaque nosso). 
Assim como ocorrem situações em que a voz do narrador, de repente, se mistura com a voz dos personagens, como vimos no exemplo acima, o inverso também acontece, ou seja, a enunciação feita na voz dos personagens se mistura com a do narrador. Como se vê no fragmento em destaque:

\begin{abstract}
Meu Deus, hoje não haverá sol, o meu filho precisa de calor. Desde a travessia do riacho que não para de tremer. Mas não é só o menino que precisa de sol. Os corpos estão encharcados, precisam de luz para secar a ferida, as roupas estão molhadas. [...] Os viajantes mergulham os olhos no céu e compreendem a importância do Sol. Sentem saudades do astro-rei que faz florescer as plantas e iluminar os caminhos. (CHIZIANE, 1999, p. 178).
\end{abstract}

Além de assumir a onisciência e uma onipresença, de mesclar sua voz com a dos personagens, o narrador de Ventos do Apocalipse também julga os fatos apresentados, opina, dá conselhos, se manifesta assim como um grande intruso, conforme se vê no fragmento abaixo:

O coração envelhecido de Minosse mergulha num galope desenfreado como uma adolescente enamorada. A alma em festa baila nas nuvens a cantiga de roda. Porque a mulher que não guarda segredo não penetra nos mistérios dos homens. Hoje, Minosse entra nos aposentos do seu senhor, confia-lhes as amarguras, é uma mulher madura, está de parabéns a pobre Minosse. (CHIZIANE,1999, p. 33 - destaque nosso).

Em seu texto "O narrador. Considerações sobre a obra de Nikolai Leskov", Walter Benjamin (1994) nos fala de dois tipos de narradores, o viajante, que tem muito para contar através da experiência de suas muitas viagens, e o camponês, que ganha a vida sem precisar sair do seu país, mas que conhece suas histórias e tradições. Para Benjamin, esses dois tipos de narradores podem ser representados pelo marinheiro comerciante e pelo camponês sedentário, respectivamente. O narrador de Ventos do Apocalipse pode ser caracterizado como o camponês sedentário, pois se fixa na sua terra e conhece profundamente a história do seu país. Nesse sentido, podemos dizer que esse narrador intruso e conselheiro de Ventos do Apocalipse constrói sua narrativa guiado por memórias fragmentárias. As histórias narradas partem de suas vivências, daquilo que viu e viveu. Suas referências de organização de pensamento e percepção do mundo têm raiz na 
oralidade. Nesses termos, ele age segundo aquilo que nos informa Benjamin quando afirma que

A experiência que passa de pessoa a pessoa é a fonte a que recorreram todos os narradores. E, entre as narrativas escritas, as melhores são as que menos se distinguem das histórias orais contadas pelos inúmeros narradores anônimos. [...] O narrador é um homem que sabe dar conselhos.[...] Aconselhar é menos responder a uma pergunta que fazer uma sugestão sobre a continuação de uma história que está sendo narrada.

(BENJAMIN, 1994, p. 198-200).

Benjamin disserta ainda a respeito do romance. O filósofo acredita que o nascimento desse gênero culminou na morte da narrativa. De acordo com ele,

$\mathrm{O}$ que distingue o romance de todas as outras formas de prosa - contos de fada, lendas e mesmo novelas - é que nem procede da tradição oral, nem a alimenta. Ele se distingue, especialmente, da narrativa. O narrador retira da experiência o que ele conta: sua própria experiência ou a relatada pelos outros. E incorpora as coisas narradas à experiência dos seus ouvintes. O romancista segrega-se. A origem do romance é o indivíduo isolado, que não pode mais falar exemplarmente sobre suas preocupações mais importantes e que não recebe conselhos e nem sabe dá-los.

(BENJAMIN, 1994, p. 201).

Ora, não é exagero afirmarmos que Benjamim se precipitou ao anunciar a morte das narrativas. Os romances das literaturas africanas de língua portuguesa recuperam essa capacidade de narrar. Como exemplo disso, podemos destacar o narrador de Ventos de Apocalipse, que narra a partir de suas vivências, julga, aconselha e não abandona suas raízes, que não se isola, mas, ao contrário, estabelece um contato profundo com o seu grupo, com as tradições de sua terra, se solidarizando quando esse grupo é atingido pelas tragédias, e se alegrando com as suas conquistas.

Além desse narrador que fala a partir de suas experiências, que assume múltiplas facetas, se identificando com as características do narrador benjaminiano, muitos outros elementos fazem das narrativas africanas de língua portuguesa obras particulares. O texto de Paulina Chiziane, por exemplo, é um trabalho artesanal, feito com minúcias, onde não há o temor da invenção e/ou renovação. Dessa forma, 
a narrativa de Chiziane, em consonância com o que nos diz Jaime Ginzburg, nos mostra que, diante das atrocidades da guerra, perde-se a capacidade de narrar de maneira convencional e, por isso, é necessário buscar outras formar de dizer, outros modos de representar. Para Guinzburg,

Representar a experiência da catástrofe em proporções tais como a História nos mostrou no século XX implica, necessariamente, uma renúncia aos modos convencionais de representação, pois estes seriam incapazes de preservar a singularidade da experiência e a perplexidade que deve acompanhá-la. O questionamento dirigido ao estatuto da linguagem, dos modos de representação e das formas artísticas tradicionais está ligado a uma busca de renovação da expressão. [...] A perda humano do Holocausto, jamais superável, leva escritores a romper com as estruturas convencionais de representação, a suspender as referências de delimitação da realidade, e a refletir melancolicamente.

(GINZBURG, 2000, p. 47).

Em Ventos do Apocalipse, podemos identificar essa inovação estética e estilística em muitos aspectos da narrativa. Uma dessas inovações ocorre no enredo da narrativa, que não segue linearmente. Como exemplo disso, podemos citar a história de Sixpence, um dos principais personagens do romance. Sixpence é o líder que assume a difícil missão de conduzir o grupo de refugiados até a Aldeia do Monte. Depois de vinte e um dias na floresta, liderando o grupo de viajantes, Sixpence chega ao local desejado, e mesmo muito doente e debilitado, é tratado como um verdadeiro heroi pelos moradores locais, sobretudo pelas mulheres. Uma dessas mulheres é Mara, que se responsabiliza por cuidar do heroi adoentado, tratando-o com uma verdadeira devoção. Depois de um tempo aos cuidados de sua atenciosa enfermeira, Sixpence se recupera da doença. Os dois passam a viver um romance proibido, já que Mara é comprometida, tem um noivo possessivo e ciumento, que passa a desconfiar da relação entre sua noiva e Sixpence. Suas suspeitas se confirmam no dia em que flagra o casal quando Mara e Sixpence passam a primeira noite juntos. Depois desse episódio, em destaque abaixo, não sabemos mais nada sobre tais personagens, cabendo a cada leitor imaginar o que terá acontecido:

Mara abandona o noivo para poupar os ouvidos a palavras azedas. O rapaz tenta persegui-la, mas depressa se apercebe da sua determinação e deixa-a prosseguir a marcha. Mara entra na 
tenda de Sixpence de rompante, profundamente agitada e só o sorriso dele é que a abranda. [...] Massaja-lhe o corpo dormente. As mãos a subir e a descer despertam o malvado. [...] Na claridade da fogueira, Sixpence olha a menina ainda ajoelhada e espreita-lhe os seios virgens que sobem e descem ao ritmo do sopro e descobre a beleza infinita no rosto imaculado. [...] Desta vez ela oferece-se mais sensual saboreando com languidez o abraço do heroi. [...] Lá fora, o noivo da Mara escuta os suspiros, sofre. (CHIZIANE, 1999, p. 198).

Desse modo, além do enredo de Ventos de Apocalipse, que não segue a linearidade típica dos padrões convencionais da narrativa de ação, o tempo da narrativa também não segue uma cronologia. $\mathrm{O}$ narrador nos apresenta algumas expressões demarcadoras de tempo; no entanto, a maior parte dos acontecimentos narrados termina e começa sem nos darmos conta de quanto tempo se passou entre um evento e outro.

Além dos elementos já citados, que caracterizam Ventos do Apocalipse como uma narrativa que foge aos modos de representação convencionais, destacamos também a linguagem utilizada pela autora, que mescla expressões das línguas locais com o português, além de misturar trechos dos mais diferentes gêneros textuais, como provérbios, lendas tradicionais moçambicanas, trechos da bíblia, ditados populares, transformando o texto em um grande mosaico. Esses artifícios de criação utilizados por Chiziane, que não se amedronta em fazer experimentalismos estéticos e estilísticos para buscar uma nova forma de representar a violência e os traumas provocados pela guerra, podem ser melhor compreendidas através da explicação de Ginzburg, em diálogo com Márcio Seligman-Silva, para as narrativas que se propõem representar situações traumáticas:

A experiência crua do passado violento e autoritário, incluindo os massacres da inquisição, o escravismo exploratório, a repressão patriarcal, constitui uma série de traumas, no sentido social discutido por Seligmann. Sua constância e complexidade nos coloca, com certeza, diante da perspectiva de realidade como catástrofe, da história como ruína. Segundo Theodor Adorno, sabemos que antagonismos da realidade se apresentam em obras de arte como antagonismos formais. Elementos como hibridismo de gêneros, relativização da verdade, problematização da linguagem, perplexidade diante do objeto tratado serão fundamentais para indicar, no interior das formas literárias, a percepção dificultada e melancólica da realidade violenta e traumática. (GUINZBURG, 2000, p. 50). 
Diante dessa dificuldade de construir uma representação convencional dos fatos traumatizantes da guerra, os escritores do pós-guerra, como é o caso de Paulina Chiziane, tiveram que buscar outras formas de representar. Em Ventos do Apocalipse, a escritora Chiziane conseguiu produzir uma obra com vários traços de originalidade, que já não se baseia nos modelos canônicos, não se fecha em padrões universalizantes, mas busca criar um modo próprio de enunciação, com uma identidade singular. Nesse sentido, de acordo com Inocência Mata, narrativas como Ventos do Apocalipse são

Obras que buscam na História a sua própria existência simbólica, funcionam como uma lógica antiépica que acaba por referenciar os ideais agónicos da revolução e do nacionalismo, através do despertar de vozes e memórias que na utopia político-social não tinham lugar. Estamos assim, perante um contra-discurso que intenta a mudança no contexto do discurso dominante [...] gerindo as suas possibilidades e as suas limitações quanto a uma "renovação discursiva”. (MATA, 2014 - destaques da autora).

Essa busca por renovação, esse contra-discurso que subverte a ordem estabelecida e vai de encontro aos padrões hegemônicos não são particularidades apenas dos romances de Chiziane, mas da maioria dos textos das literaturas africanas de língua portuguesa, como também das literaturas pós-coloniais. Essas literaturas pós-coloniais, ao trazerem à tona temáticas delicadas como as guerras civis, intentam contar outra versão para a história, não mais a dos vencedores, mas a dos vencidos, mobilizando "estratégias contra-discursivas que visam a desligitimação dum projecto de nação monocolor pensado sob o signo da ideologia nacionalista". (MATA, 2000).

Nesse contexto, podemos afirmar que a brutalidade da violência provocada pela guerra é o tema central de Ventos do Apocalipse. Do início ao fim do romance, as imagens da violência, consequência da guerra civil moçambicana, são mostradas das mais variadas formas: no pai que esconde a comida da família, na mãe que assassina o filho, na criança que vê os pais serem enterrados vivos, nos irmãos que matam um ao outro, entre tantas outras. No entanto, por mais chocantes que essas imagens possam parecer, nesse romance a representação mais espantosa da violência ocorre em consequência da fome. A fome é uma presença insistente nessa obra, provocando tensões e desequilíbrios nas relações, sejam elas entre os seres humanos ou entre humanos e animais. 
Dessa forma, podemos afirmar que, assim como o narrador, que se manifesta de maneira onipresente, a fome também se mostra em todo o romance, e de tão presente, passa a se configurar como mais uma personagem da narrativa. Para o narrador, é a fome que motiva todas as guerras, conforme se vê no fragmento abaixo:

Nos regatos ressequidos os quadrúpedes aparavam toda a erva. Os homens comeram todos os quadrúpedes e ficaram sem sustento. Fizeram-se gatos, comeram todos os ratos. Cobras e lagartos. A bicharada acabou e ficaram de novo sem sustento. Daí fizeramse macacos saltando de árvore em árvore, comendo frutas silvestres, e até descobriram novos cardápios que adicionaram aos tradicionalmente conhecidos. As pessoas caíam como cajus maduros. A alegria vem da barriga, se há guerras no mundo é pela posse do pão, na casa onde há fome todos ralham e ninguém tem razão. (CHIZIANE, 1999, p. 16-17).

Para o narrador, a fome transforma a relação entre as pessoas, pois a violência da fome produz a fome de violência. Para sobreviver, na luta por alimentos, os indivíduos violentam a si mesmos e, se necessário, violentam aos outros. Conforme é apresentado no romance, a fome desestabiliza as relações familiares: os maridos abandonam mulher e filhos, pois já não conseguem sustentá-los; as mães escondem comida dos filhos e, em casos mais extremos, pensam em matá-los, numa tentativa desesperada, pois, a ausência de um familiar possibilitaria que sobrasse mais comida para os sobreviventes:

O desespero agora é maior do que antes. O marido abandona o lar. A mãe esconde o pedaço de milho roubado para comê-lo quando a criança adormecer. $\mathrm{O}$ valor do homem mede-se pela quantidade de géneros alimentícios que possui. [...] O cinturão da fome aperta firme, o minuto transforma-se num dia e a hora multiplica-se em muitas e muitas eternidades. [...] $\mathrm{O}$ novo bebê é indesejável à família, é rival, compete com os mais velhos por um pedaço de alimento. $\mathrm{O}$ irmão que visita não é bem recebido. Os casais mais amorosos desfazem-se, os mais idosos são abandonados à sorte e as doces mãezinhas sentem lá no fundo o desejo inconfessável de eliminar os frutos do próprio ventre porque já não há mais comida que chegue. (CHIZIANE, 1999, p. 109). 
Além de violentar as relações entre os seres humanos, a fome altera a relação entre os humanos e os animais. Para tentar sobreviver à escassez de alimentos provocada pela guerra, os moradores de Mananga mudam seus hábitos alimentares, e a carne de alguns animais, que jamais seria alimento em uma circunstância comum, tornase uma comida por muitos desejada. O excerto destacado exemplifica essa situação:

Os gritos dos meninos em combate confundem-se com os grasnidos dos corvos. Uma das aves traça espirais em queda acompanhada pelos hurras dos vencedores. Hoje haverá petisco, afirmam eles. Mas o povo diz que os corvos não comem porque cheiram mal e dão muito azar. Preconceitos dos tempos da fartura. Agora o lema é: aquilo que te come, come-o tu. (CHIZIANE, 1999, p. 27).

Em tempos de fome, o que importa é comer, escolher o alimento é um luxo que os refugiados de guerra não podem ter. Tudo pode virar comida, pois o que importa é sobreviver, manter o estômago cheio, independente do alimento que seja utilizada para esse fim:

Um ratinho deixa aparecer a cabeça no limiar do esconderijo. Assustase. Regressa ao buraco e ouvem-se novos chios. O pobrezinho ergue a cabeça de novo, hesita, corre em direção à porta, mas a tia Rose lança a pesada mão, asfixia-o, recolhe o carinhosamente para $o$ cestinho de palha. E suspira: ah, meu pequenino, ficas aqui para um petisco. (CHIZIANE, 1999, p. 81).

Com o avançar da guerra, a miséria também avança, e chegará um momento em que não restará nem ratos, nem corvos. É preciso matar a fome, antes que ela mate a todos, e já que não se pode escolher os alimentos, até os animais de estimação podem se transformar em comida. "À distância o uivar dos cães é igual ao choro dos meninos, pouco falta para que eles morram e alguém já propôs que se comam". (CHIZIANE, 1999, p. 64). A fome se manifesta de maneira cada vez mais violenta, ela está sempre presente, e para saciá-la, os humanos passam a consumir alimentos que antes eram consumidos apenas pelos animais.

Os viajantes tentam repousar, o estômago está alerta, não adormece, incomoda. Pela centésima vez olham para as panelinhas vazias. [...] Os olhos identificavam em volta. O chão está coberto de ervas frescas, rasteiras. É desta erva que os porcos se alimentam e engordam. [...] 
Colhem as ervas dos porcos e os tubérculos das malangas, mas falta fogueira para eliminar as toxinas da verdura. [...] $\mathrm{O}$ estômago reclama e o povo abandona os rodeios e os devaneios. Com as duas mãos pegam no tubérculo da malanga, trincam, saboreiam. [...] Sabem que estão a abrir as portas para uma diarreia mortal, mas o que eles são senão cadáveres em movimento? (CHIZIANE, 1999, p. 179).

A fome é tão violenta com os seres humanos que eles passam a agir como animais. A falta de comida animaliza, enfraquece, desespera, enlouquece e mata. Em um contexto de guerra, a fome torna-se mais mortífera do que as armas, matando não só os seres vivos, mas as tradições, os costumes, pois, "no tempo de fome, a única lei é a da sobrevivência”. (CHIZIANE, 1999, p. 182).

Entre todas as vítimas da fome, as crianças são as que mais sofrem. As crianças que antes eram festejadas pela família, acabam se transformando em um transtorno, um problema a mais:

O menino tem fome e chora, a menina cansa-se de brincar e adormece. Dorme meu menino, a mamã partiu ao raiar da luz, já é meio dia e já está quase a regressar. Não sofras tanto, porque ela foi realizar o sacrifício sublime para que não sofras mais de fome. Ah, teimoso! Chupa a minha mama caída, entretém-te e tenta adormecer. (CHIZIANE, 1999, p. 98).

As mães se sacrificam para tentar aliviar a fome dos filhos, os pais se desesperam por não conseguirem alimento para a família, a fome não espera, vai se alastrando cada vez mais forte, como um furacão, destruindo a todos em sua volta. Os indivíduos famintos vão ficando cada vez mais magros, raquíticos, seu corpo vai passando por um processo de deformação. Depois de um longo tempo vivendo de migalhas, os refugiados da guerra transformam-se em seres fantasmagóricos:

Não há velhos nem novos, a turbulência da vida nivelou-lhes as idades. Não se distingue o homem da mulher pelos contornos do corpo. A fome comeu as curvas das ancas, as laranjas dos seios, deixando apenas os ossos. Nos homens cresce apenas a barba que supera a exuberância da floresta medonha. Os ventres de todos competem em volume com qualquer mulher no último mês de gestação. (CHIZIANE, 1999, p. 184). 
Diante do exposto, podemos constatar que representar a história traumática de uma nação atingida pela brutalidade da guerra não é uma empreitada das mais fáceis. Para cumprir essa árdua tarefa, Paulina Chiziane não hesitou em fazer experimentalismos estéticos e estilísticos, criando uma história impactante, mas carregada de lirismo, nos mostrando que para se dizer o indizível, é necessário se buscar outras formas de dizer. Nesse sentido, é importante ressaltar que,

Para a pesquisa literária, é necessário o desafio de verificar como, nas formas literárias, encontramos lapsos, descontinuidades, contradições, subversões de convenções, rupturas com gêneros tradicionais, questionamentos a respeito da capacidade comunicativa e expressiva da literatura. Devemos redobrar a atenção sobre esses elementos quando interessam não como fim em si mesmos, como experimentos formais, mas quando associando a temas que, direta ou indiretamente, digam respeito ao impacto brutal da violência social. [...] Para a catástrofe, guardemos a perplexidade, a inquietação, jamais a linearidade ou a banalização. (GINZBURG, 2000, p. 50-51).

Perplexidade, certamente essa é a melhor palavra para definir a reação dos leitores que entram em contato com a narrativa Ventos do Apocalipse. Durante toda a narrativa, o leitor é tomado por uma sensação de desconforto e inquietude. O cenário de desolação provocado pela guerra, descrito de maneira minuciosa pelo narrador, a violência latente, que se manifesta nas mais variadas situações, a morte que de tão recorrente acaba por se tornar banal, deixam o leitor em estado de suspensão. No entanto, de todas essas imagens, a encenação da fome que vai aniquilando os seres humanos até transformá-los em seres desfigurados são as que provocam mais perplexidade.

Essa reação do leitor diante da narrativa nos mostra a importância da produção literária de Paulina Chiziane enquanto instrumento de denúncia e de reflexão crítica. Esse comprometimento ético de Paulina Chiziane entra em consonância com o discurso de Inocência Mata, que, ao falar sobre a importância da literatura como elemento capaz de preencher os vazios da História oficial, assim se manifesta:

Foi a literatura que "nos" informou sobre as sensibilidades discordantes, os eventos omitidos do discurso oficial [...], as vozes em dissenso, as visões menos monocolores, menos apologéticas e menos subservientes ao Poder Político. O ponto de partida desse protocolo de transmissão de "conteúdos históricos" é a ideia de que 
o autor - em pleno domínio e responsabilidade sobre o que diz, ou faz as suas personagens dizerem, psicografa os anseios e demónios de sua época, dando voz àqueles que se colocam, ou são colocados, à margem da "voz oficial": daí poder pensar que o indizível de uma época só encontra lugar na literatura - e porque a História é parcial e parcelar, como equaciona Saramago, a "ficção desafia a História com o discurso que a reinventa e compensa a sua parcialidade". (MATA, 2006, p. 34 - destaques da autora).

Ventos do Apocalipse é uma narrativa de guerra, onde a luta mais importante não é contra o exército inimigo, mas contra a fome, inimiga invisível, que ataca sorrateiramente, minando pouco a pouco a força de suas vítimas. E é contra ela que os refugiados combatem durante toda a narrativa. O romance de Chiziane provoca desconforto até no interlocutor mais insensível. Ao ler Ventos do Apocalipse, qualquer leitor sentirá, de algum modo, os impactos da guerra, pois é impossível sair da leitura dessa obra sem uma sensação indigesta em relação às múltiplas manifestações de violência que fazem parte do nosso mundo.

\begin{abstract}
The study analyzes the novel Ventos do Apocalipse (1999), written by Paulina Chiziane, evaluating some aesthetic and stylistic aspects of the work that allows the reader to understand how it original and innovative shows that to write about the atrocities of war it becomes necessary to seek other form to say, other ways of representing.
\end{abstract}

Keywords: Ventos do Apocalipse. Paulina Chiziane. Literature. War. Representation

Referências

BENJAMIN, Walter. O narrador. Considerações sobre a obra de Nikolai Leskov. In: Obras escolhidas: Magia e técnica, arte e política. Tradução de Sérgio Paulo Rouanet. São Paulo: Brasiliense, 1994. 
CHIZIANE, Paulina. Ventos do Apocalipse. Lisboa: Editorial Caminho, 1999.

GUINSBURG, J. Autoritarismo e literatura - a história como trauma. Disponível em: http:/sites.unifra.br/Portals/35/Artigos/.../autoritarismo.pdf. Acesso em: 25 set. 2014.

MATA, Inocência. A crítica literária africana e a teoria pós-colonial: um modismo ou uma exigência? In: Ipotesi. Juiz de Fora, v.10, n.1, n.2, pág. 33-44, jan-jun, jul-dez, 2006.

MATA, Inocência. O pós-colonial nas literaturas africanas de língua portuguesa. Disponível em: bibliotecavirtual.clacso.org.ar/ar/libros/aladaa/mata.rtf. Acesso em: 25. Set. 2014.

\section{SSS}






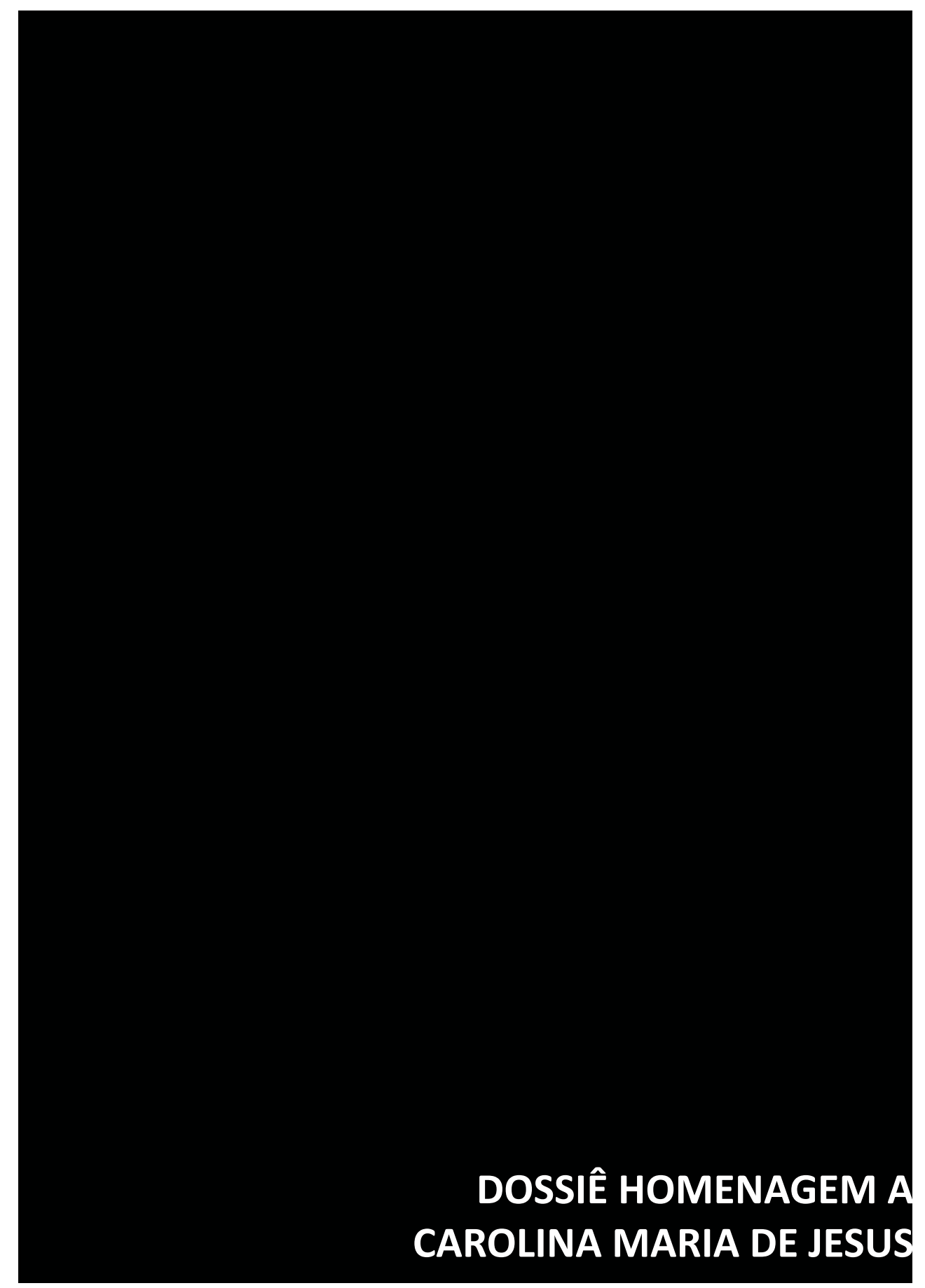

